\title{
Avaliação das propriedades físicas e mecânicas de blocos de solo-cimento formulados com coprodutos siderúrgicos
}

\author{
Evaluation of physical and mechanical \\ properties of soil-cement bricks \\ formulated with steel co-products
}

\author{
Mário Andrean Macedo Castro ${ }^{1}$, Fiama Gomes da Costa ${ }^{1}$, Suellen Cristina Borba ${ }^{1}$,
} Elias Fagury Neto ${ }^{1}$, Adriano Alves Rabelo ${ }^{1}$

\author{
${ }^{1}$ Faculdade de Engenharia de Materiais - FEMAT - UNIFESSPA, Folha 17, Quadra 04, Lote Especial - 68505-080, \\ Marabá, PA \\ e-mail: marioandrean10@hotmail.com; fiama_gomes13@hotmail.com; suellenc.ufpa@gmail.com; \\ fagury@unifesspa.edu.br; adriano@unifesspa.edu.br
}

\begin{abstract}
RESUMO
Este trabalho tem por objetivo caracterizar o desempenho de resistência mecânica e absorção de água de blocos solo-cimento para alvenaria, após 28 dias de cura, com a incorporação limite dos seguintes coprodutos siderúrgicos em substituição parcial ao solo: adições de até 20 \% em massa do pó de balão coletado em altoforno, até $10 \%$ de poeiras de despoeiramento de aciaria elétrica, e até $20 \%$ de escória granulada de forno elétrico a arco. As formulações propostas incluem adições simultâneas de pós obtidos do descarte da produção de blocos solo-cimento, onde a substituição parcial ao solo foi de até $20 \%$ em massa. Os resultados obtidos sugerem a potencialidade de uso dos resíduos siderúrgicos em blocos intertravados de solo-cimento para alvenaria sustentável, como alternativa de aplicação para esses resíduos. Verificou-se a possibilidade de bons resultados confrontando os valores exigidos por norma (absorção de água $<20 \%$ e resistência mecânica $>2,0$ $\mathrm{MPa}$ ) com destaque quando se utilizou $20 \%$ pó de balão juntamente com $10 \%$ de reuso do bloco solocimento; $10 \%$ de escória de aciaria ou $20 \%$ de escória de aciaria juntamente com $10 \%$ de reuso do bloco solo-cimento; e 2,5\% de pó de despoeiramento juntamente com $20 \%$ de reuso do bloco solo-cimento.
\end{abstract}

Palavras-chave: Coprodutos siderúrgicos, solo-cimento, alvenaria sustentável, estabilização.

\section{ABSTRACT}

This work aims to characterize the mechanical resistance performance and water absorption of soil-cement blocks for masonry, after 28 days of moist curing, with the incorporation limit of the following steel coproducts to partial replacement of soil: up to $20 \%$ by weight of balloon blast furnace dust powder additions, $10 \%$ of dedusting dust secondary from electric arc furnace, and $20 \%$ of granulated slag of electric arc furnace. The proposed formulations also evaluated simultaneous additions of soil-cement blocks discarded, after granulated by crushing, with partial replacement of soil in up to $20 \%$ by mass. The results suggest the potential use of steel residues in soil-cement interlocked blocks for sustainable masonry, as applying alternative to this waste. It was found that the results that stood out, comparing standard specification (water absorption < $20 \%$ and strength $>2.0 \mathrm{MPa}$ ), the results that stood out were using $20 \%$ powder flask along with a $10 \%$ reuse of the soil-cement block; $10 \%$ of steel slag or $20 \%$ of steel slag with $10 \%$ reuse of soil-cement block; and $2.5 \%$ dusting powder with $20 \%$ reuse of the soil-cement block.

Keywords: Steel co-products, soil-cement, sustainable masonry, stabilization.

\section{INTRODUÇÃO}

As atividades de fabricação de gusa e ferro-ligas geram grandes quantidades de subprodutos, que a princípio seriam descartados na natureza sem nenhum tipo de reaproveitamento, motivando novas técnicas de reciclagem. Usinas integradas de produção de aço geram materiais coprodutos que apresentam algumas dificuldades 
para a sua total reutilização, dentre os quais o chamado pó de balão, um pó do coletor de alto-forno, escórias da redução do gusa em alto-forno e da fundição do aço no forno panela e refino secundário no forno elétrico a arco, assim como pós de despoeiramento da aciaria.

O pó de balão coletado no sistema de limpeza a seco de gases dos altos-fornos apresenta uma quantidade gerada de aproximadamente $20 \mathrm{~kg} / \mathrm{t}$ a $45 \mathrm{~kg} / \mathrm{t}$. de ferro gusa [1, 2]. Eventualmente pode ser aglomerado juntamente com outros coprodutos e matérias-primas em unidades de sinterização de aglomerados permeáveis para retornarem como carga no alto-forno ou serão descartados, gerando passivos ambientais [3].

A escória de aciaria gera cerca de $150 \mathrm{~kg} / \mathrm{t}$. de aço produzido, dependendo das matérias-primas utilizadas e do processo de fabricação de aço empregado, mediante a utilização de fornos elétricos ou conversores LD a oxigênio. Considerando que isso representa $15 \%$ do total produzido mundialmente, somente no ano de 2008 foram produzidos aproximadamente 200 milhões de toneladas deste resíduo [4].

Por sua vez o pó de despoeiramento ou pó de aciaria elétrica é um resíduo sólido, rico em ferro e zinco, gerado como particulado das emissões provenientes da produção de aço em fornos elétricos a arco, que são filtrados pelo sistema de despoeiramento. Estima-se que sejam gerados de $15 \mathrm{~kg}$ a $20 \mathrm{~kg}$ de pó de despoeiramento por tonelada de aço produzido [5, 6].

Recomenda-se o uso de subprodutos industriais em produtos cerâmicos, especialmente quando estes materiais adicionam versatilidade para os sistemas de materiais cimentícios, além das vantagens óbvias de benefícios ambientais. Isso é relevante para diferentes profissionais que atuam na área de construção e trabalham em países em desenvolvimento, que têm de enfrentar os desafios globais, enquanto confrontado com o aumento da pressão sobre a transparência, as boas práticas, bem como sobre a capacidade de realizar suas operações de forma mais sustentável [7].

Solo-cimento em blocos intertravados para alvenaria de vedação é produzido por prensagem, seguida de cura e secagem, não sendo necessária sua queima, e por isso recebem a denominação de tijolos ecológicos. Seu uso facilita a passagem das instalações e tem execução mais rápida que em paredes monolíticas do mesmo material, devido sua excelente regularidade dimensional e nivelamento facial. Possibilitam a eliminação da argamassa de assentamento e revestimento devido ao uso de cola branca. Sua aparência e qualidade final são marcadamente superiores aos seus homólogos, necessitando apenas de impermeabilização e uma cobertura de acabamento. Esta tecnologia reduz, portanto, o uso de energia e emissões de dióxido de carbono de forma vital para incrementar a sustentabilidade da construção civil, minimizando o consumo de recursos naturais e possibilitando materiais mais eficientes [8].

Diferentes subprodutos têm sido relatados como material de substituição à argila para a produção de blocos intertravados de solo-cimento para alvenaria, tais como a utilização de resíduo do beneficiamento de caulim [9], palha de arroz e braquiária [10], utilização de resíduos de concreto [11], resíduos de alumina e cinza de carvão [12]. Entretanto, são muito escassas as publicações que utilizem resíduos da indústria do aço.

Este trabalho teve por objetivo avaliar as potencialidades de blocos de solo-cimento para uso em alvenaria sustentável com incorporação de coprodutos siderúrgicos, juntamente com o reaproveitamento do descarte da produção de blocos solo-cimento, com o intuito de reciclar estes subprodutos.

\section{MATERIAIS E MÉTODOS}

Os materiais utilizados neste trabalho foram: solo caulinítico, cimento Portland composto CPII-Z32, os coprodutos siderúrgicos: pó de despoeiramento (PD) e pó de balão (PB) e escória proveniente de forno elétrico a arco (EAE), e blocos de solo-cimento defeituosos finamente granulados (RB).

A composição química da escória foi verificada utilizando-se um espectrômetro de fluorescência de raios X por energia dispersiva EDX-720/800HS da Shimadzu, e utilizou-se um Panalytical, modelo Axios Minerals para o pó de despoeiramento e pó de balão. A composição mineralógica foi analisada a partir de um difratômetro da Panalytical, com goniômetro PW3050/60 e com tubo de raios X cerâmico de ânodo de Cu $\left(\mathrm{K}_{\alpha 1}=1,5406 \AA\right)$, modelo PW3373/00.

A granulometria das amostras de solo, RB, EAE, PD e PB foram analisadas por peneiramento, utilizando as peneiras de 30, 40, 70, 100 e 200 mesh e agitador eletromagnético de peneiras da marca Bertel. A norma que conduziu o ensaio foi a NBR 7181/1984, versão corrigida: 1988 [13].

Para a determinação dos Limites de Atterberg do solo, limite de liquidez, limite de plasticidade e índice de plasticidade, utilizou-se o aparelho Casagrande e placa de vidro esmerilhada, ambos da marca Solotest. Os ensaios foram conduzidos segundo a norma NBR 6459/84 [14].

Foram confeccionados 6 blocos de cada formulação, onde variou-se a mistura do pó RB dos blocos de solo-cimento e coprodutos siderúrgicos. A quantidade de cimento permaneceu constante em 14,8\%, ou 
seja, o traço utilizado foi 1:6 em volume de cimento em relação ao solo em todas as formulações.

As Tabelas 1, 2 e 3 apresentam as formulações utilizadas. As misturas foram realizadas em betoneira, com a prévia britagem da escória do forno elétrico de aciaria para obter a granulometria inferior 15 mesh como os demais coprodutos. Após a mistura em betoneira, as formulações foram conformadas em blocos de 296 x 146 x 70 mm com dois furos de 81 mm de diâmetro em prensa hidráulica semiautomática, marca Sahara, modelo TH-2. Em seguida os blocos eram empilhados e umedecidos durante quatro dias, sob uma lona para manter a temperatura entre 25 a $30{ }^{\circ} \mathrm{C}$ evitando o aparecimento de trincas. $\mathrm{O}$ tempo de cura foi de 28 dias.

Tabela 1: Formulação utilizada para incorporação de pó de balão (PB) aos blocos de solo-cimento e adições do pó de blocos rejeitados (RB) com $14,8 \%$ de cimento.

\begin{tabular}{c|c|c|c}
\hline FORMULAÇÕES & SOLO (\%) & PB (\%) & RB (\%) \\
\hline $\mathrm{F}_{0}$ & 80,2 & 5 & 0 \\
\hline $\mathrm{F}_{1}$ & 75,2 & 10 & 0 \\
\hline $\mathrm{F}_{2}$ & 70,2 & 15 & 0 \\
\hline $\mathrm{F}_{3}$ & 65,2 & 20 & 0 \\
\hline $\mathrm{F}_{4}$ & 70,2 & 5 & 10 \\
\hline $\mathrm{F}_{5}$ & 65,2 & 10 & 10 \\
\hline $\mathrm{F}_{6}$ & 60,2 & 15 & 10 \\
\hline $\mathrm{F}_{7}$ & 55,2 & 20 & 10 \\
\hline $\mathrm{F}_{8}$ & 60,2 & 5 & 20 \\
\hline $\mathrm{F}_{9}$ & 55,2 & 10 & 20 \\
\hline $\mathrm{F}_{10}$ & 50,2 & 15 & 20 \\
\hline $\mathrm{F}_{11}$ & 45,2 & 20 & 20 \\
\hline
\end{tabular}

Tabela 2: Formulação utilizada para incorporação de escória elétrica de aciaria (EAE) aos blocos de solo-cimento e adições do pó de blocos rejeitados (RB) com 14,8\% de cimento.

\begin{tabular}{c|c|c|c}
\hline FORMULAÇÕES & SOLO (\%) & EAE (\%) & RB (\%) \\
\hline $\mathrm{F}_{0}$ & 85,2 & 0 & 0 \\
\hline $\mathrm{F}_{1}$ & 80,2 & 0 & 5 \\
\hline $\mathrm{F}_{2}$ & 75,2 & 5 & 5 \\
\hline $\mathrm{F}_{3}$ & 70,2 & 10 & 5 \\
\hline $\mathrm{F}_{4}$ & 80,2 & 5 & 0 \\
\hline $\mathrm{F}_{5}$ & 60,2 & 20 & 5 \\
\hline $\mathrm{F}_{6}$ & 75,2 & 0 & 10 \\
\hline $\mathrm{F}_{7}$ & 70,2 & 5 & 10 \\
\hline $\mathrm{F}_{8}$ & 65,2 & 10 & 10 \\
\hline $\mathrm{F}_{9}$ & 75,2 & 10 & 0 \\
\hline $\mathrm{F}_{10}$ & 55,2 & 20 & 10 \\
\hline
\end{tabular}


Tabela 3: Formulação utilizada para incorporação de pó de despoeiramento (PD) aos blocos de solo-cimento e adições do pó de blocos rejeitados (RB) com $14,8 \%$ de cimento.

\begin{tabular}{c|c|c|c}
\hline FORMULAÇÕES & SOLO (\%) & PD (\%) & RB (\%) \\
\hline$F_{0}$ & 75,2 & 10,0 & 0 \\
\hline$F_{1}$ & 77,7 & 7,5 & 0 \\
\hline$F_{2}$ & 80,2 & 5,0 & 0 \\
\hline$F_{3}$ & 82,7 & 2,5 & 0 \\
\hline$F_{4}$ & 65,2 & 10,0 & 10 \\
\hline$F_{5}$ & 67,7 & 7,5 & 10 \\
\hline$F_{6}$ & 70,2 & 5,0 & 10 \\
\hline$F_{7}$ & 72,7 & 2,5 & 10 \\
\hline$F_{8}$ & 55,2 & 10,0 & 20 \\
\hline$F_{9}$ & 57,7 & 7,5 & 20 \\
\hline$F_{10}$ & 60,2 & 5,0 & 20 \\
\hline$F_{11}$ & 62,7 & 2,5 & 20 \\
\hline
\end{tabular}

Os corpos de prova foram preparados segundo os requisitos da norma NBR 10834/2012 [15]. Os blocos passaram por dois tipos de caracterização tecnológica: ensaios de absorção de água pelo método de Arquimedes e de resistência à compressão, realizado em prensa manual hidráulica, marca Solotest. Os ensaios foram realizados seguindo a norma NBR 10836/2013 [16].

\section{RESULTADOS E DISCUSSÃO}

Os resultados obtidos da análise granulométrica são apresentados na Figura 1 para o solo e coprodutos siderúrgicos, assim como o pó solo-cimento de blocos eventualmente descartados na produção ou estocagem após granulados (RB).

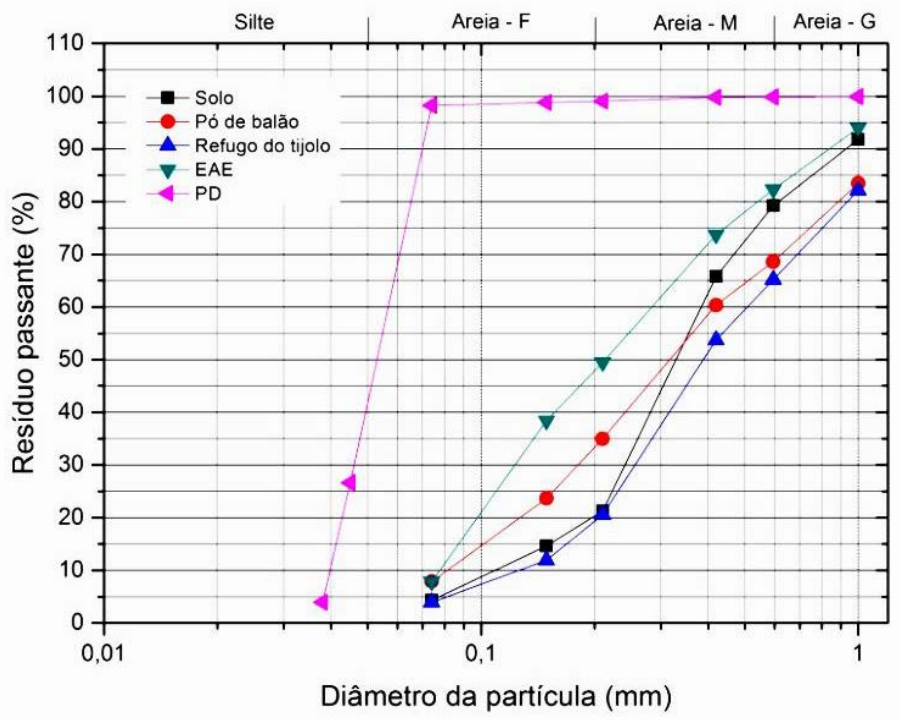

Figura 1: Análise granulométrica dos pós de solo e coprodutos siderúrgicos.

Com base na análise das curvas, é possível identificar que o solo possui baixa fração argilosa e os solos arenosos bem graduados, com razoável quantidade de silte mais argila, são os mais indicados, pois requerem baixo consumo de cimento [9]. O solo utilizado tem característica apropriada para o uso em misturas de solo-cimento, onde os grãos de areia grossa e pedregulhos tem como função o preenchimento, uma vez que estes são agregados inertes, enquanto o cimento tem ação aglomerante das partículas mais finas, proporcionando resistência mecânica $[11,17]$.

Os resíduos utilizados são compostos basicamente por granulometrias correspondentes à faixa típica de areia 
fina e média, com exceção do PD que é mais fino e parte da distribuição corresponde a partículas de granulometria equivalente ao silte. Entretanto, de acordo com os resultados da Figura 1, a presença de partículas finas de PD pode resultar em menor poder aglomerante entre o cimento e areia devido ao mecanismo de estabilização do cimento, proporcionando perda na resistência à compressão dos blocos solo-cimento [18]. O reaproveitamento de escória de aciaria (EAE) com o reaproveitamento da produção de blocos solo-cimento em pó (RB) propicia uma maior quantidade de sílica na mistura.

O solo não apresentou caracteristica plástica, o que pode ser observado na Tabela 2, que apresenta os limites de Atterberg. Os demais solos da literatura apresentados para comparação caracterizam-se por serem argiloarenoso e arenoso, respectivamente [19, 20].

Tabela 2: Limites de Atterberg.

\begin{tabular}{c|c|c|c}
\hline PLASTICIDADE & SOLO & Ref. [18] & Ref. [19] \\
\hline L.L. (\%) & 30,0 & 33 & 15,3 \\
\hline L.P. (\%) & 13,5 & 19 & 14,4 \\
\hline I.P. & 0,3 & 14 & 0,9 \\
\hline
\end{tabular}

O fato do solo apresentar baixa plasticidade confirma o resultado da análise granulométrica, que apresentou maior quantidade de areia e pouca quantidade de silte, consequentemente o índice de plasticidade apresentou o menor valor. Comparando o resultado deste trabalho com a literatura, verifica-se a necessidade de se certificar que o solo de fato seja pouco plástico para a fabricação de materiais solo-cimento [9, 19, 20].

A Tabela 3 apresenta a composição dos coprodutos siderúrgicos utilizados, mas há flutuações, principalmente na escória, a cada corrida dos fornos da aciaria. Todos os resíduos apresentam alto teor do íon ferro. É importante destacar que esses resultados foram obtidos para resíduos provenientes de sucata não fragmentada. Embora um estudo comparativo seja necessário, o uso de equipamento fragmentador (Shredder) permite selecionar uma sucata muito mais limpa, portanto mais homogênea e com menor emissão de gases, favorecendo a redução parcial das impurezas a serem estabilizadas no produto cerâmico [21].

Tabela 3: Composição predominante dos resíduos/coprodutos siderúrgicos.

\begin{tabular}{c|c|c|c|c|c|c|c|c|c|c|c|c|c}
\hline Resíduo & $\mathbf{C a O}$ & $\mathbf{S i O}_{2}$ & $\mathbf{M g O}$ & $\mathbf{P}_{\mathbf{2}} \mathbf{O}_{5}$ & $\mathbf{F e O}$ & $\mathbf{Z n O}$ & $\mathbf{P b O}$ & $\mathbf{A l}_{2} \mathbf{O}_{3}$ & $\mathbf{C r}_{2} \mathbf{O}_{3}$ & $\mathbf{F}$ & $\mathbf{K}_{2} \mathbf{O}$ & $\mathbf{M n O}$ & $\mathbf{S O}_{3}$ \\
\hline $\mathrm{PB}$ & 6,977 & 8,613 & 1,301 & 0,140 & 61,190 & - & - & 7,974 & 0,001 & 0,001 & 0,571 & 1,368 & 0,165 \\
\hline $\mathrm{PD}$ & 6,148 & 5,022 & - & - & 48,947 & 28,160 & 2,743 & - & 0,277 & - & 2,109 & 2,115 & 3,733 \\
\hline $\mathrm{EAE}$ & 21,447 & 14,885 & 9,312 & 0,276 & 53,013 & - & - & 3,479 & 0,228 & 1,079 & 0,063 & 4,304 & 0,035 \\
\hline
\end{tabular}

O pó de balão (PB) é constituído, predominantemente, por uma mistura de óxidos de ferro (hematita e goetita) com quartzo e finos de carvão e calcário [cristais de calcita- $\mathrm{CaCO}_{3}$ e e gibsita - $\mathrm{Al}(\mathrm{OH})_{3}$ ], em decorrência da grande quantidade de pó arrastado do sistema de limpeza a seco dos gases dos altos-fornos. Embora de baixo caráter poluidor, é classificado como Resíduo Classe I - Perigoso, conforme parâmetros definidos pela norma NBR 10004 [22], exigindo cuidados específicos. Entretanto, é importante destacar que essa classificação é devido ao elevado teor de fenóis $\left(\mathrm{C}_{6} \mathrm{H}_{5} \mathrm{OH}\right)$ encontrado especificamente nesse tipo de material, cujo ponto de fusão é de $41^{\circ} \mathrm{C}$.

A norma NBR 10004 classifica como resíduo tóxico as poeiras provenientes do filtro de manga primário e secundário de controle de emissão de gases empregado na produção de aço em fornos elétricos, onde seus constituintes perigosos são o cromo hexavalente, chumbo e cádmio. Além da presença de chumbo, traços detectados de bromo (0,365 \%), cromo $(0,277 \%)$ e cobre $(0,225 \%)$ (não apresentados Tabela 3$)$, consequentemente, dificultam o gerenciamento desse resíduo. A presença do chumbo, entretanto, pode tornar interessante o uso deste resíduo em tijolos convencionais devido ao efeito fundente. Destaca-se o grande teor de Fe (48,947 \%) e Zn (28,160 \%) no pó de despoeiramento (PD). Pesquisas anteriores indicaram que as fases mineralógicas predominantes são magnetita, ferrita espinélio $\left(\mathrm{FeO}^{\circ} \mathrm{Fe}_{2} \mathrm{O}_{3}\right)$, ferrita espinélio de zinco ou franklinita $\left(\mathrm{ZnO}^{\circ} \mathrm{Fe}_{2} \mathrm{O}_{3}\right)$, jacobsita $\left(\mathrm{MnO}^{*} \mathrm{Fe}_{2} \mathrm{O}_{3}\right)$, soluções sólidas desses três espinélios, faialita $\left[\left(\mathrm{FeO}_{2} \cdot \mathrm{SiO}_{2}\right]\right.$ e zincita $(\mathrm{ZnO})$ [23]. 
A escória de aciaria é um resíduo sólido gerado em operações pirometalúrgicas, que contém sílica sólida à temperatura ambiente e impurezas provenientes dos metais processados. É classificada como resíduo inerte, entretanto, vale diferenciar a escória do forno panela (refino redutor) e a utilizada nesse trabalho, proveniente do forno elétrico a arco do refino secundário (oxidante). A primeira retém 2,5 vezes o teor de cal virgem, empregada para retirar e neutralizar os elementos fósforo, enxofre e silício no processo de refino do gusa para a produção de aço. Pode apresentar instabilidade volumétrica devido à expansão por hidratação da cal livre e desintegração, embora seja baixa para a escória do refino oxidante. Um procedimento para reduzir ao mínimo o fenômeno pode ser realizado através do envelhecimento da escória finamente granulada em pátio, regando-a com água natural ou água quente para conseguir hidratar os elementos instáveis [24].

Embora o solo utilizado seja essencialmente caulinítico e, consequentemente apresenta coloração creme-clara, todos os resíduos utilizados nesse trabalho proporcionaram modificações crescentes na coloração para tons mais escuros nos blocos solo-cimento em função da presença de hematita e manganês, o que normalmente apresenta maior aceitação dos consumidores. Tradicionalmente é aplicado verniz como acabamento sobre as alvenarias de solo-cimento, o que certamente contribuirá para o aprisionamento dos coprodutos superficiais. Difratogramas de raios X dos blocos solo-cimento com 10\% em peso dos resíduos avaliados identificaram a predominância das seguintes fases: caulinita, goetita, quartzo, calcita e jacobsita.

As Figuras 2, 3 e 4 permitem avaliar os resultados de absorção de água dos blocos solo-cimento com os diferentes teores dos coprodutos siderúrgicos e adições dos blocos pulverizados reutilizados, onde a linha horizontal indica o valor médio máximo de $20 \%$ exigido na norma NBR 10836, enquanto para valores individuais exige valores menor ou igual a $22 \%$. A formulação sem adições de resíduos apresentou valor médio para a absorção de água de 24 \%, valor este que não se enquadra nos parâmetro da norma.

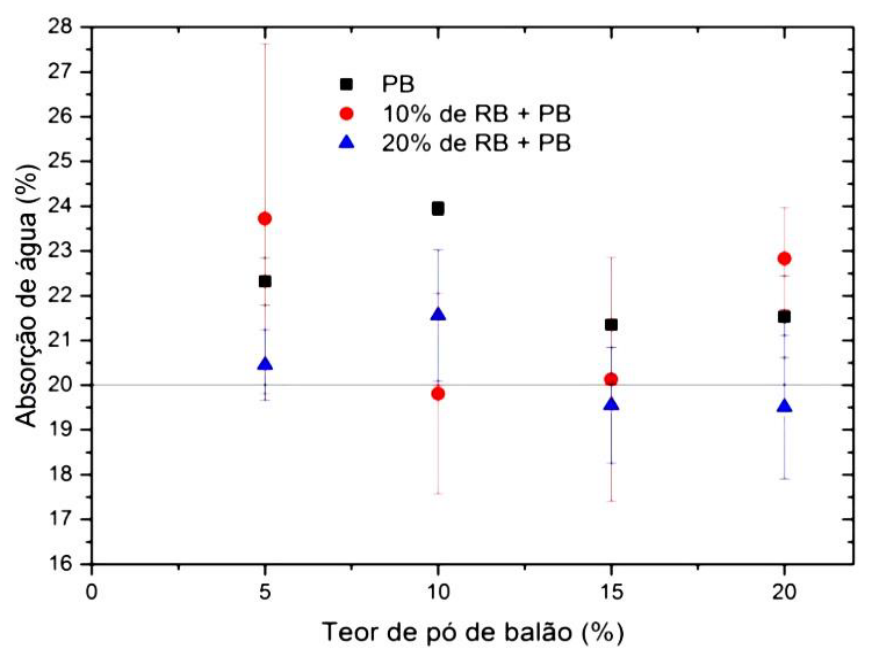

Figura 2: Absorção de água para blocos solo-cimento usando incorporações do pó de balão (PB) e pó de solo-cimento (RB) de blocos pulverizados. 


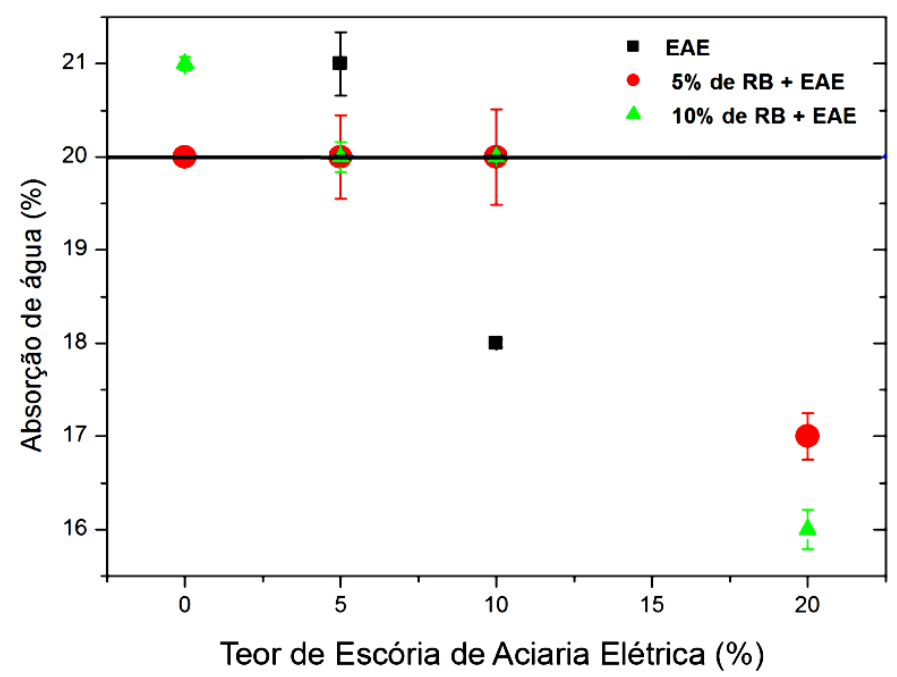

Figura 3: Absorção de água para blocos solo-cimento com incorporações da escória de aciaria (EAE) e pó solo-cimento (RB) de blocos pulverizados.

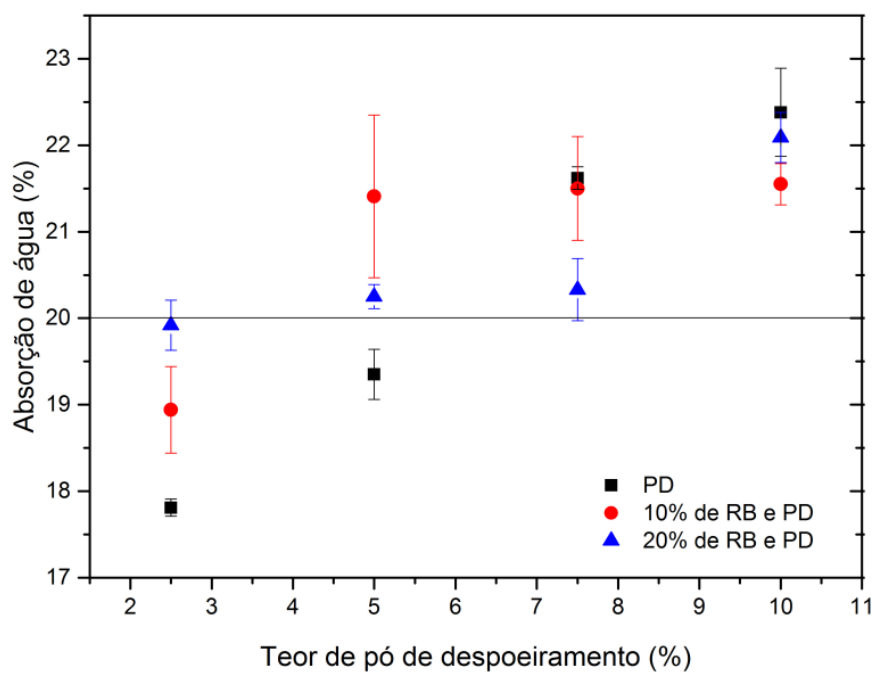

Figura 4: Absorção de água para blocos solo-cimento usando incorporações do pó de despoeirameto (PD) e pó de blocos solo-cimento (RB) de blocos pulverizados.

Em relação aos valores verificados de absorção de água com adições de pó de balão (PB), os blocos solo-cimento somente atingiram valores satisfatórios com o reaproveitamento da própria produção de solocimento (RB) quando se utiliza teores acima de $10 \%$ de PB (F5, F10 e F11) permitindo o consumo de eventuais blocos descartados durante a produção, estocagem ou transporte, com a diminuição da porosidade nos produtos finais.

No caso da incorporação de escória de aciaria elétrica (EAE), pode-se observar que é possível fabricar blocos solo-cimento com o teor máximo verificado de EAE, ou seja, 20\% de escória com adição simultânea de $\mathrm{RB}$, tanto com $5 \%$ como $10 \%$. Quando se adiciona $10 \%$ de EAE os valores de absorção de água coincidem com o limite especificado. Estes resultados sugerem a possibilidade do uso de maiores quantidades de EAE.

Apenas as formulações propostas com o menor teor do pó de despoeiramento (PD) satisfizes os valores exigidos por norma (F2, F3, F7, e F11), onde a formulação F2 utilizou o maior teor de desse resíduo entre essas formulações, contendo 5 \% de PD, e acima desse valor ocorre um aumento linear indesejável da absorção de água.

Os resultados de resistência mecânica à compressão dos blocos solo-cimento estão apresentados nas Figuras 5, 6 e 7. A formulação do corpo de prova de referência, não apresentada nas figuras, apresentou média de resistência à compressão de 1,1 MPa, valor este aquém ao exigido pela norma. A resistência à com- 
pressão em conformidade à norma, apresentam média de valores maior ou igual a 2,0 MPa (em destaque nas figuras) e valor individual maior ou igual a 1,7 MPa [11].O erro apresentado nos valores mostra que os blocos apresentaram dispersão de resistência à compressão, inerente ao método de fabricação.

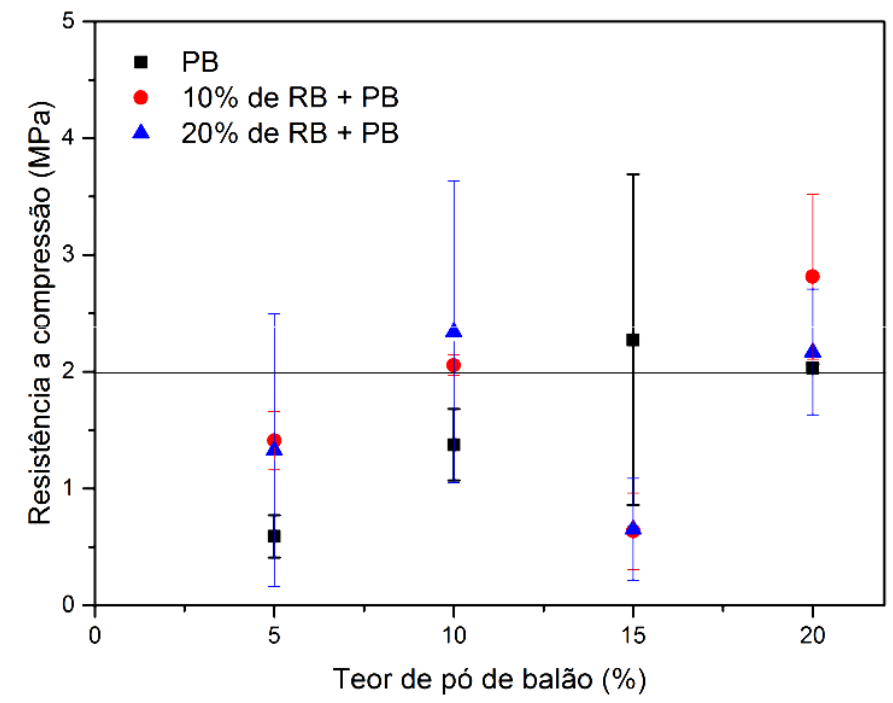

Figura 5: Resistência à compressão para blocos solo-cimento usando incorporações do pó de balão (PB) e pó de solocimento $(\mathrm{RB})$ de blocos pulverizados.

Embora o erro da medida com 15 \% de PB tenha sido elevado, as formulações que se destacaram no desempenho de resistência a compressão foram as com maiores teores sem adição de RB, ocorrendo algum ganho ao se adicionar RB para $20 \%$ de PB, mas pode ocorrer o comprometimento do resultado de absorção de água. Confrontando os desempenhos de resistência à compressão e absorção de água, sugerindo as formulações F5 e F11 como apropriadas para alvenaria.

O resultado de resistência à compressão que atende simultaneamente a exigência de absorção de água para blocos solo-cimento com incorporações da EAE foi satisfatório apenas para a formulação com 20 \% de escória do forno elétrico a arco e $10 \%$ de reaproveitamento de pó solo-cimento (RB). Estudos utilizando escória Fe-Si-Mn atingiram a especificação de 2,0 MPa somente depois de 60 dias de cura [25].

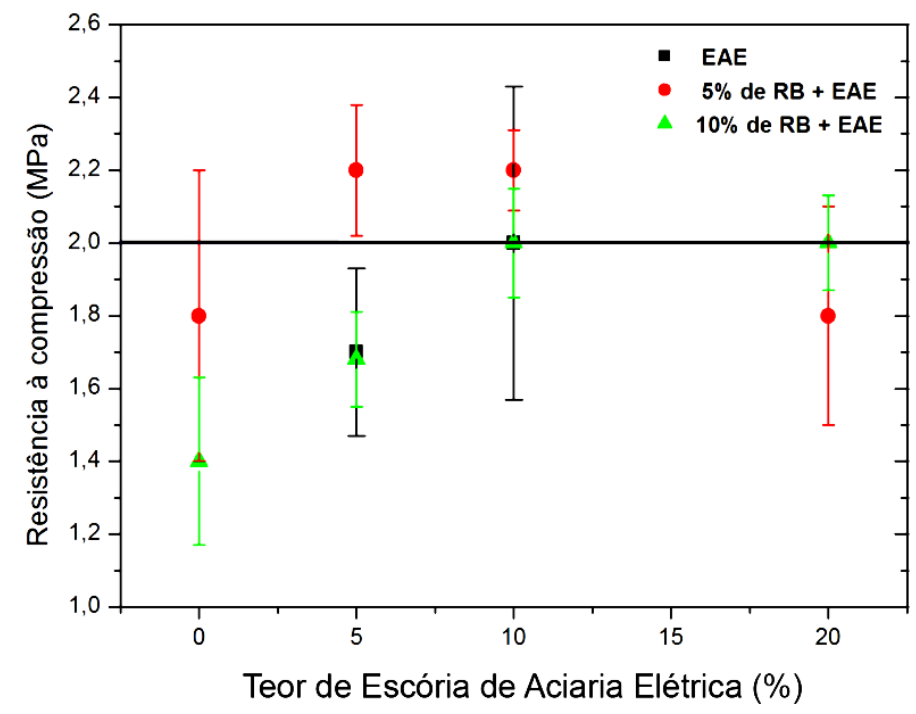

Figura 6: Resistência à compressão para blocos solo-cimento com incorporações da escória de aciaria (EAE) e pó solocimento (RB) de blocos pulverizados.

Devido a algumas composições com PD não terem resistido ao processo de hidratação e apresentarem trincas, somente as formulações com 2,5 e 7,5 \% foram submetidas ao teste de resistência à compressão. Para 
os resultados dos blocos com PD as composições F2, F3 e F7 também não alcançaram os exigidos, ao contrário da formulação F11, que atingiu a média de 2,3 MPa, estando em conformidade à norma. A composição F7 contém o menor teor de PD e o maior teor de RB, criando uma proporção mais adequada entre os coprodutos siderúrgicos e cimento.

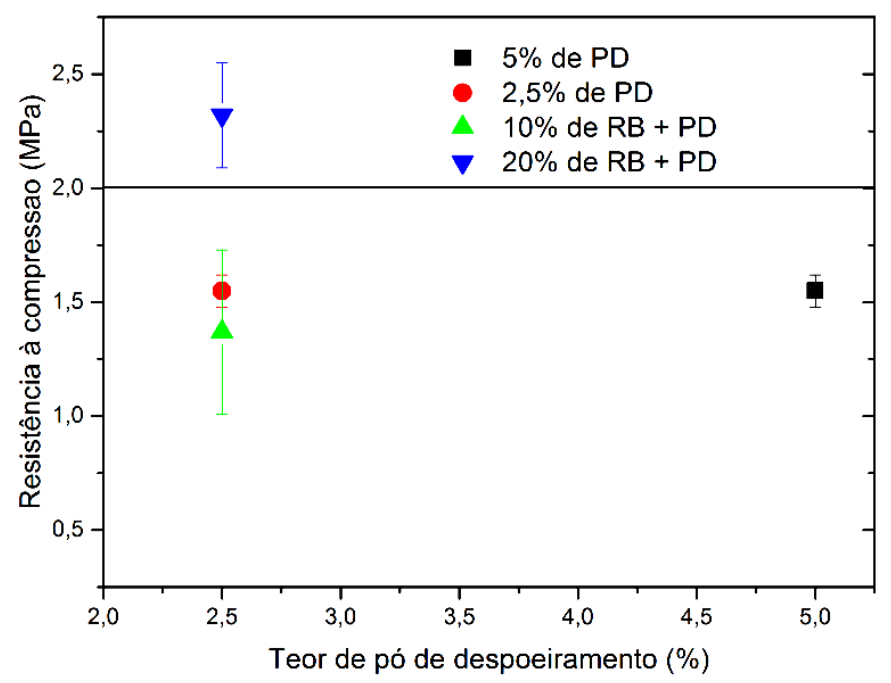

Figura 7: Resistência à compressão para blocos solo-cimento usando incorporações do pó de despoeirameto (PD) e pó de blocos solo-cimento (RB) de blocos pulverizados.

A alteração do traço de cimento é uma alternativa para resultar em maior coesão dos grânulos e atingir valores de resistência maiores, conjugando com a dosagem dos subprodutos incorporados. Comparando-se os resultados obtidos com os observados na literatura com incorporação do resíduo de caulim em corpos de prova cilíndricos [5], valores similares de resistência à compressão foram alcançados com 28 dias de cura, embora o desempenho de absorção de água com os resíduos siderúrgicos tenda a ser inferior. Quando se utilizou a incorporação de rejeitos orgânicos [10], que tendem a dificultar a cura do cimento diminuindo seu efeito aglomerante, pode-se verificar que houve uma dispersão maior dos valores de resistência à compressão utilizando corpos de prova de dimensões inferiores ao do presente trabalho, consequentemente a absorção de água apresentou melhores valores.

\section{CONCLUSÕES}

A utilização de resíduos ou coprodutos siderúrgicos na produção de blocos de solo-cimento para alvenaria isoladamente ou juntamente com o reuso do próprio bloco solo-cimento, pode proporcionar economia e a diminuição do passivo ambiental, além de ganhos para as características estéticas e tecnológicas do solocimento.

O aprisionamento dos resíduos siderúrgicos avaliados não deve apresentar toxidade após o completo aprisionamento nos blocos solo-cimento com a aplicação de verniz como acabamento usualmente utilizado nas superfícies das alvenarias.

Verificou a possibilidade de bons resultados em conformidade a norma técnica brasileira, quanto às exigências de absorção de água e resistência mecânica, com destaque para as formulações contendo:

- 20\% pó de balão juntamente com $10 \%$ de reuso do bloco solo-cimento;

- 10\% de escória ou $20 \%$ de escória de aciaria juntamente com 10\% de reuso do bloco solo-cimento;

- 2,5\% de pó de despoeiramento juntamente com $20 \%$ de reuso do bloco solo-cimento.

\section{AGRADECIMENTOS}

Os autores agradecem a UNIFESSPA pelo Programa Institucional de Bolsa de Extensão, ao Prof. Dr. Rômulo Simões Angélica (IG-UFPA) pelas análises mineralógicas dos coprodutos e a colaboração das empresas Dorim Construções Tijolos Ecológicos Ltda. e Sinobras (Siderúrgica Norte Brasil S.A.). 


\section{BIBLIOGRAFIA}

[1] SINOBRAS - Siderúrgica Norte Brasil S.A., 2013 Relatório de sustentabilidade, Relatório. Marabá, 2013. http://www.sinobras.com.br/novo/images/pdf/Relatorio_de_Sustentabilidade_2013.pdf, acessando em maio de 2015.

[2] OLIVEIRA, L.C.P., Gestão de Coprodutos. Estudo Prospectivo do Setor Siderúrgico: 2008. Brasília: Centro de Gestão e Estudos Estratégicos, 2008. (Nota Técnica), 2008.28 pp. http://www.abmbrasil.com.br/epss/arquivos/documentos/2011_4_19_9_59_59_88597.pdf, acessado em maio de 2015.

[3] OLIVEIRA, M.R.C., MARTINS, J., “Caracterização e classificação do resíduo sólido "pó do balão", gerado na indústria siderúrgica não integrada a carvão vegetal: estudo de um caso na região de Sete Lagoas/MG”, Química Nova, v. 26 n.1, pp. 5-9, jan./fev. 2003.

[4] MILANEZ, B., PORTO, M.F., “A ferro e fogo: impactos da siderurgia para o ambiente e a sociedade após a reestruturação dos anos 1990”, In: IV Encontro Nacional da Anppas, 20 p., Brasília, DF, Brasil, 4 - 6 junho 2008.

[5] FAY, L., Aproveitamento de resíduos siderúrgicos para a fabricação de elementos construtivos para alvenarias na construção civil, Tese de D.Sc., COPPE/UFRJ Rio de Janeiro, RJ, Brasil, 2006.

[6] LOBATO, N.C.C., VILLEGAS, E.A., MANSUR, M. B. "Levantamento de possíveis rotas processuais para a reutilização do pó de aciaria elétrica”, In: XX Congresso Brasileiro de Engenharia Química, 17660, Florianópolis, SC, 19 a 22 Outubro 2014.

[7] OTI, J.E., KINUTHIA, J.M., BAI, J., "Compressive strength and microstructural analysis of unfired clay masonry bricks”, Engineering Geology, v. 109, pp. 230-240, 2009.

[8] OTI, J.E., KINUTHIA, J.M., "Stabilised unfired clay bricks for environmental and sustainable use”, Applied Clay Science, v. 58 pp. 52-59, 2012.

[9] CASTRO, S.H., Incorporação de resíduos de caulim em solo-cimento para construções civis, Dissertação M.Sc., PPG-ECA/UFCG, Campina Grande, PB, Brasil, 2008.

[10] FERREIRA, R. C., GOBO, J. C. C., CUNHA, A. H. N. "Incorporação de casca de arroz e de braquiária e seus efeitos nas propriedades físicas e mecânicas de tijolos de solo-cimento”, Engenharia Agrícola, Jaboticabal, v. 28, n. 1, pp. 1-11, jan./mar. 2008.

[11] SOUZA, M.I B., SEGANTINI, A.A.S., PEREIRA, J.A. "Tijolos prensados de solo-cimento confeccionados com resíduo de concreto”, Revista Brasileira de Engenharia Agrícola e Ambiental, v. 12, n. 2, pp. 205-212, mar./abr. 2008.

[12] MIQUELEIZ, L., RAMIREZ, F., OTI, J.E., SECO, A., KINUTHIA, J.M., OREJA, I., URMENETA, P., “Alumina filler waste as clay replacement material for unfired brick production”, Engineering Geology, v. 163, pp. 68-74, 2013.

[13] ASSOCIAÇÃO BRASILEIRA DE NORMAS TÉCNICAS, Solo: Análise granulométrica. NBR 7181. Rio de Janeiro: ABNT, 1988.

[14] ASSOCIAÇÃO BRASILEIRA DE NORMAS TÉCNICAS, Solo: Determinação do limite de liquidez. NBR 6459. Rio de Janeiro: ABNT, 1984.

[15] ASSOCIAÇÃO BRASILEIRA DE NORMAS TÉCNICAS, Bloco de solo-cimento sem função estrutural: Requisitos. NBR 10834. Rio de Janeiro: ABNT, 2012.

[16] ASSOCIAÇÃO BRASILEIRA DE NORMAS TÉCNICAS, Bloco de solo-cimento sem função estrutural: Análise dimensional, determinação da resistência à compressão e da absorção de água - Método de ensaio. NBR 10836. Rio de Janeiro: ABNT, 2013.

[17] SEGANTINI, A.A.S. Utilização de solo-cimento plástico em estacas escavadas com trado mecânico em Ilha Solteira-SP, Tese de D.Sc., Faculdade de Engenharia Agrícola/UNICAMP Campinas, SP, Brasil, 2000.

[18] LIMA, T.V., Estudo da produção de blocos de solo-cimento com matérias primas do núcleo urbano da cidade de Campos dos Goytacases-RJ, Dissertação de Me, Centro de Ciência e Tecnologia/UENF Campos dos Goytacases, RJ, Brasil, 2006.

[19] MIELI, P. H., Avaliação do tijolo modular de solo-cimento como material na construção civil, Trabalho de Conclusão de Curso, COPPE/UFRJ Rio de Janeiro, RJ, Brasil, 2009.

[20] ROLIM, M. M., FREIRE, W. J., BERALDO, A. L., “Análise comparativa da resistência à compressão simples de corpos de prova, tijolos e painéis de solo-cimento”, Revista Brasileira de Engenharia Agrícola e Ambiental, v. 3, n. 1, pp.89-92, 1999. 
[21] VERMEULEN, I., BLOCK, C., CANEGHEM, J.V., et al., "Sustainability assessment of industrial waste treatment processes: The case of automotive shredder residue” Resources, Conservation and Recycling, v. 69, pp. 17-28, 2012.

[22] ASSOCIAÇÃO BRASILEIRA DE NORMAS TÉCNICAS, Resíduos sólidos - Classificação. NBR 10004. Rio de Janeiro: ABNT, 2004.

[23] HAGI A.M., HAGI R.D., "Residues and effluents-processing and environmental considerations”, In: The Minerals, Metals and Materials Society, Warrendale, PA, pp. 177-125, 1992.

[24] RUBIO A.R., CARRETERO, J. G. “La aplicación de las escorias de aceria en carreteras”, Ingenieria Civil, v.80, p. 5-8, 1991.

[25] FERREIRA, W.L., REIS, E.L., LIMA, R.M.F., "Incorporation of residues from the minerometallurgical industry in the production of clay-lime brick", Journal of Cleaner Production, v. 87, pp. 505510, 2015. 